\title{
Neuronal MHC Class I Molecules are Involved in Excitatory Synaptic Transmission at the Hippocampal Mossy Fiber Synapses of Marmoset Monkeys
}

\author{
Adema Ribic • Mingyue Zhang - Christina Schlumbohm • \\ Kerstin Mätz-Rensing • Barbara Uchanska-Ziegler • \\ Gabriele Flügge $\cdot$ Weiqi Zhang $\cdot$ Lutz Walter $\cdot$ Eberhard Fuchs
}

Received: 10 November 2009/ Accepted: 1 March 2010/Published online: 16 March 2010

(C) The Author(s) 2010. This article is published with open access at Springerlink.com

\begin{abstract}
Several recent studies suggested a role for neuronal major histocompatibility complex class I (MHCI) molecules in certain forms of synaptic plasticity in the hippocampus of rodents. Here, we report for the first time on the expression pattern and functional properties of MHCI molecules in the hippocampus of a nonhuman primate, the common marmoset monkey (Callithrix jacchus). We detected a presynaptic, mossy fiber-specific localization of MHCI proteins within the marmoset hippocampus. MHCI molecules were present in the large, VGlut1-positive, mossy fiber terminals, which provide input to CA3 pyramidal neurons. Furthermore, whole-cell recordings of CA3 pyramidal neurons in acute hippocampal slices of the common marmoset demonstrated that application of antibodies which specifically block MHCI proteins caused a
\end{abstract}

Lutz Walter and Eberhard Fuchs share senior authorship.

Electronic supplementary material The online version of this article (doi:10.1007/s10571-010-9510-3) contains supplementary material, which is available to authorized users.

A. Ribic $(\varangle) \cdot$ C. Schlumbohm · G. Flügge · E. Fuchs Clinical Neurobiology Laboratory, German Primate Center, Leibniz Institute for Primate Research, Kellnerweg 4, 37077 Göttingen, Germany

e-mail: aribic@cnl-dpz.de

A. Ribic $\cdot$ L. Walter

Primate Genetics Laboratory, German Primate Center,

Leibniz Institute for Primate Research, Göttingen, Germany

K. Mätz-Rensing

Infection Pathology Unit, German Primate Center,

Leibniz Institute for Primate Research, Göttingen, Germany

E. Fuchs

Department of Neurology, Medical School,

Georg-August-University, Göttingen, Germany significant decrease in the frequency, and a transient increase in the amplitude, of spontaneous excitatory postsynaptic currents (sEPSCs) in CA3 pyramidal neurons. These findings add to previous studies on neuronal MHCI molecules by describing their expression and localization in the primate hippocampus and by implicating them in plasticity-related processes at the mossy fiber-CA3 synapses. In addition, our results suggest significant interspecies differences in the localization of neuronal MHCI molecules in the hippocampus of mice and marmosets, as well as in their potential function in these species.

Keywords Calbindin - CA3 - GFAP · Piccolo · Neuronal plasticity · PSD95 - sEPSC · VGAT · VGlut1 . VGlut 2

Abbreviations
CA1 Cornu ammonis 1
CA3 $\quad$ Cornu ammonis 3

G. Flügge · E. Fuchs

DFG Research Center Molecular Physiology of the Brain (CMPB), Göttingen, Germany

M. Zhang · W. Zhang

Laboratory of Molecular Psychiatry, Department of Psychiatry, Westfälische Wilhelms University, Münster, Germany

B. Uchanska-Ziegler Institut für Immungenetik, Charité-Universitätsmedizin Berlin, Berlin, Germany 
CNS Central nervous system

GFAP Glial fibrillary acidic protein

LTD Long term depression

LTP Long term potentiation

$\mathrm{mAb} \quad$ Monoclonal antibody/antibodies

mEPSCs Miniature excitatory postsynaptic currents

MHC Major histocompatibility complex

MHCI Major histocompatibility complex class I

PSD95 Postsynaptic density protein of $95 \mathrm{kDA}$

sEPSCs Spontaneous excitatory postsynaptic currents

VGAT Vesicular GABA transporter

VGlut1 Vesicular glutamate transporter 1

VGlut2 Vesicular glutamate transporter 2

\section{Introduction}

Major histocompatibility complex class I (MHCI) molecules belong to a large and extremely polymorphic family of cell-surface receptors involved in innate and adaptive immune responses in vertebrates (Solheim 1999). Typical MHCI molecules are heterotrimers composed of a transmembrane heavy chain, a noncovalently attached $\beta$-2-microglobulin subunit, and a short peptide comprising 8-15 amino acids that is derived from self or foreign antigens and is presented to cytotoxic $\mathrm{T}$ lymphocytes (Solheim 1999; Cresswell et al. 2005). Although virtually all nucleated cells express MHCI molecules, their expression in neurons has remained debatable, as the central nervous system (CNS) is considered immunologically silent (Aarli 1983). However, recent data from rodents demonstrate that MHCI molecules are expressed on the neurons of the CNS and are involved in the modulation of certain plasticity processes in the developing and adult brain (Corriveau et al. 1998; Huh et al. 2000; Goddard et al. 2007; McConnell et al. 2009). MHCI proteins localize to postsynaptic sites in the mouse hippocampus, and hippocampal neurons of MHCI-deficient mice display abnormalities in synapse structure and in basal synaptic transmission (Goddard et al. 2007). MHCI genes are well conserved in mammals; however, there are a number of differences in the organization, structure, and function of these genes between rodents and primates (Kumanovics et al. 2003). Our group has previously demonstrated the expression of certain MHCI genes in the brain of the adult marmoset monkey; their expression patterns in this species appeared comparable to the ones observed in rodents (Rölleke et al. 2006). Here, we describe the expression pattern of a subset of MHCI molecules localized exclusively on the presynaptic side of mossy fiber-CA3 synapses in the marmoset hippocampus. Furthermore, we investigated the properties of excitatory synaptic transmission in acute hippocampal slices of the marmoset monkey and we found that application of antibodies against MHCI interfered with synaptic transmission. The results obtained in this study confirm the emerging role of MHCI molecules in neuronal plasticity and indicate interspecies differences in the expression patterns and functional properties of these proteins in the hippocampus.

\section{Materials and Methods}

Animals

Fifteen common marmoset monkeys (Callithrix jacchus, 14 males and 1 female) were obtained from the breeding colony at the German Primate Center, Göttingen, Germany. All animal experiments were conducted in accordance with the European Communities Council Directive of November 24, 1986 (86/EEC) and with the National Institutes of Health Guide for the Care and Use of Laboratory Animals, and were approved by the Lower Saxony Federal State Office for Consumer Protection and Food Safety. We investigated healthy, 1 day to 6 years old animals which were also used for other ongoing studies. For expression studies, brain sections were from male animals ranging in age from 1 day old to 6 years old (kindly provided in part by Dr. B. Czéh). Slices for electrophysiology were from 2-, 4-, and 5-year old animals. In all cases, we used the minimum number of animals required to obtain consistent data.

\section{Anti-MHCI Antibodies}

For the detection of MHCI proteins, monoclonal HCA2 and HC10 antibodies were used (Stam et al. 1986, 1990). These antibodies react with polymorphic determinants of classical and some non-classical human MHCI molecules located in the extracellular alpha-1 domain (Stam et al. 1986, 1990; Seitz et al. 1998; Gauster et al. 2007). The antibodies were purified from HCA2 and $\mathrm{HC} 10$ hybridoma supernatants (kindly provided by B. Uchanska-Ziegler) via ammonium sulfate precipitation followed by purification using Protein G Sepharose (GE Healthcare, Munich, Germany) according to the manufacturer's instructions. Antibodies were later dialyzed with Amicon concentrators (Milipore, Billerica, MA, USA) against sterile $0.1 \mathrm{M}$ phosphate-buffered saline (PBS; $\mathrm{pH}$ 7.2) and adjusted to concentrations of 2 and $1.5 \mathrm{mg} / \mathrm{ml}$, respectively.

\section{Brain Sections}

For immunohistochemistry, marmosets were terminally anesthetized with an overdose of ketamine $(50 \mathrm{mg} / \mathrm{ml})$, 
xylazine $(10 \mathrm{mg} / \mathrm{ml})$, and atropine $(0.1 \mathrm{mg} / \mathrm{ml})]$. Animals were then perfused transcardially with $0.9 \%$ saline, followed by $200 \mathrm{ml}$ of fixative containing $4 \%$ paraformaldehyde in $0.1 \mathrm{M}$ sodium phosphate buffer $(\mathrm{pH}$ 7.2) for $15 \mathrm{~min}$. The heads were postfixed using the same fixative and the brains were carefully removed from the skulls one day later. After cryoprotection in 0.1 M PBS ( $\mathrm{pH} 7.2$ ) containing $30 \%$ sucrose, serial coronal sections $(40 \mu \mathrm{m})$ were prepared using a cryostat.

\section{Immunocytochemistry for Light Microscopy}

Coronal cryosections $(40 \mu \mathrm{m})$ were collected from marmoset brains containing the hippocampal formation, washed briefly in PBS and quenched of endogenous peroxidase activity by $30 \mathrm{~min}$ incubation at room temperature (RT) in $0.5 \% \mathrm{H}_{2} \mathrm{O}_{2}$ in distilled water. Sections were rinsed in PBS, blocked for $1 \mathrm{~h}$ at RT [3\% normal horse serum and $0.03 \%$ Triton-X-100 (Sigma) in PBS], incubated $16 \mathrm{~h}$ at $4^{\circ} \mathrm{C}$ with either monoclonal HCA2 IgG $(1 \mathrm{mg} / \mathrm{ml}, 1: 500$ dilution in $3 \%$ normal horse serum and $0.03 \%$ Triton-X100 , in PBS) or with control mouse IgG (Sigma), and washed again. Sections were then incubated with biotinylated horse anti-mouse IgG (Vector Laboratories, Burlingame, CA, USA; 1:200 dilution in 3\% normal horse serum and $0.03 \%$ Triton-X-100, in PBS) for $1 \mathrm{~h}$ at RT. After washing, sections were incubated with avidin-biotinhorseradish peroxidase (Vectastain Elite ABC Kit, Vector Laboratories; 1:100 dilution in 3\% normal horse serum and $0.03 \%$ Triton-X-100, in PBS) for $1 \mathrm{~h}$ at $\mathrm{RT}$, washed in PBS and then again in $0.05 \mathrm{M}$ Tris $/ \mathrm{HCl}(\mathrm{pH}$ 7.2) prior to $\mathrm{DAB}$ detection (DAB detection with or without nickel enhancement was performed according to the manufacturer's instructions; DAB-Kit, Vector Laboratories). For immunocytochemistry with $\mathrm{HC} 10$ antibody, the epitope retrieval step was perfomed prior to all other steps by incubating the sections for $20 \mathrm{~min}$ in $10 \mathrm{mM}$ sodium citrate buffer preheated to $80^{\circ} \mathrm{C}$. Sections were later brought to room temperature, washed in PBS and quenched of endogenous peroxidase activity, followed by blocking and incubation in monoclonal $\mathrm{HC} 10 \mathrm{IgG}(1 \mathrm{mg} / \mathrm{ml}, 1: 500$ dilution in $3 \%$ normal horse serum in PBS). All further steps were performed as described above with omission of Triton-X-100 in all the steps. Sections were washed in $0.05 \mathrm{M}$ Tris/ $\mathrm{HCl}(\mathrm{pH} 7.6)$ and again in 0.1 M PBS prior to xylol clearance, dehydration, and coverslipping with Eukitt mounting medium (Kindler, Freiburg, Germany). For Timm's stain (according to Seress et al. 2001), hippocampal slices $(1 \mathrm{~mm})$ were immersed in $0.4 \% \mathrm{Na}_{2} \mathrm{~S}$ for $30 \mathrm{~min}$, and then fixed for $16 \mathrm{~h}$ in $1 \%$ paraformaldehyde and $1.25 \%$ glutaraldehyde. The fixed slices were cryoprotected, frozen, and cut into $30-\mu \mathrm{m}$ sections which were mounted and dried. Sections were then immersed in developer consisting of $30 \mathrm{ml}$ gum Arabic (50\%), $5 \mathrm{ml}$ citrate buffer (2 M, pH 3.7), $15 \mathrm{ml}$ hydroquinone (5.67\%), and $0.25 \mathrm{ml} \mathrm{AgNO}_{3}(17 \%)$ for at least $60 \mathrm{~min}$. Digital images of immunostained tissue sections were acquired using the Axiophot II microscope (Zeiss). Final images were assembled in Corel PHOTO-PAINT X3 and are a composition of 4-6 images encompassing the entire hippocampal formation.

Immunofluorescence and Confocal Microscopy

Antibodies used in double-labeling experiments were applied sequentially and blocking steps were performed using normal serum of host species from which respective secondary antibodies were derived. Cryostat sections (40 $\mu \mathrm{m})$ of marmoset brains containing the hippocampal formation were rinsed in PBS. Non-specific antibody binding sites were blocked with $3 \%$ normal serum and $0.03 \%$ Triton-X-100 (Sigma) in PBS for $1 \mathrm{~h}$ at room temperature. Primary antibodies were used at following dilutions (diluted in 3\% normal serum and $0.03 \%$ Triton-X100, in PBS): monoclonal mouse HCA2, 1:500; control mouse IgG 1:500 (Sigma); rabbit anti-PSD95 (Cell Signaling Technology, Danvers, MA, USA), 1:200; rabbit anti-Piccolo, 1:200; rabbit anti-VGlut1, 1:1,000; rabbit anti-VGlut2, 1:200; rabbit anti VGAT, 1:200; rabbit antiGFAP, 1:200 (all from Synaptic Systems, Göttingen, Germany); rabbit anti-calbindin, 1:200 and sheep anti-TH, 1:200 (both from Chemicon International Ltd., Hampshire, UK). Secondary antibodies (Alexa 488-coupled donkey anti mouse, Alexa 568-coupled goat anti-rabbit and Alexa 594-coupled donkey anti-sheep, Molecular Probes, Invitrogen, Leiden, Netherlands) were used at 1:500 dilution (diluted in 3\% normal serum and $0.03 \%$ Triton-X-100, in PBS). After the antibody incubation steps, sections were washed in PBS and floated/mounted on Histobond slides in distilled water, allowed to dry overnight at $4^{\circ} \mathrm{C}$ and coverslipped with mounting medium (Aqua-Polymount, Polysciences Inc., Warrington, PA, USA).

Confocal microscopy was performed using a laserscanning microscope (LSM 5 PASCAL, Zeiss) with argon $(488 \mathrm{~nm})$ and helium/neon $(543 \mathrm{~nm})$ lasers. Confocal analysis was performed in multiple-tracking mode to avoid bleed through between channels. High magnification images were obtained as $z$-series stacks of a region containing mossy fiber terminals at a resolution of 2,048 $\times 2,048$ using an Apochromat $63 \times$ oil objective $(\mathrm{NA}=1.4)$ and immersion oil (Immersol, Zeiss; refractive index $=1.518$ ). The $543 \mathrm{~nm}$ laser was always used with a smaller detection pinhole diameter than the $488 \mathrm{~nm}$ laser to produce optical sections of comparable thickness for colocalization analysis. For substantia nigra, images were taken from single plane at a resolution of $1,024 \times 1,024$ using an 
Apochromat $63 \times$ oil objective $(\mathrm{NA}=1.4)$ and immersion oil (Immersol, Zeiss; refractive index $=1.518$ ). For quantification of colocalization signals, intensity correlation coefficients (ICQ, Li et al. 2004) were obtained using the ImageJ colocalization plug-in (Abramoff et al. 2004) for a minimum of three images per animal. These values were compared between the two groups using the Student's $t$-test (GraphPad Prism version 4 for Windows, San Diego, CA, USA). The region of interest (ROI) was defined using the green channel (MHCI signal).

\section{PCR Cloning of MHC Class I Transcripts}

Isolation of the common marmoset MHC class I cDNA sequence was carried out by reverse transcriptase polymerase chain reaction (RT-PCR). $1 \mu \mathrm{g}$ of total brain RNA was reverse transcribed using oligo-d(T) primer (GACTCGAGTCGACATCGA(T) ${ }_{17}$ ) and $400 \mathrm{U}$ of reverse transcriptase (Promega, Mannheim, Germany). An aliquot of this reaction was used as template in a PCR containing the primers. The primers were designed using Primer3 program (Rozen and Skaletsky 2000) and were intended to amplify full length marmoset MHC class I transcripts. Primer sequences were carrying BamHI restriction sites and were as follows: forward $5^{\prime}$-CACGGATCCCACTTTACAAGCCGTGAGAGAC- ${ }^{\prime}$, reverse $5^{\prime}$-CACGGATCC CTCCTGTTGCTCTCGGGGGCCTTG-3'. Caja-G*1 (Accesion number: U59637) was obtained and cloned in pEXPR-IBA103 (IBA Technologies, Göttingen, Germany).

\section{Protein Extraction and Immunoblot Analysis}

Brains were immediately removed from terminally anesthetized animals [by an overdose of ketamine $(50 \mathrm{mg} / \mathrm{ml})$, xylazine $(10 \mathrm{mg} / \mathrm{ml})$, and atropine $(0.1 \mathrm{mg} / \mathrm{ml})]$. Hippocampi were quickly dissected and homogenized using a Dounce homogenizer (tight pestle) in ice-cold homogenization buffer consisting of $50 \mathrm{mM}$ Tris/ $\mathrm{HCl}(\mathrm{pH} 7.4), 7.5 \%$ glycerol, $150 \mathrm{mM} \mathrm{NaCl}, 1 \mathrm{mM}$ EDTA, $1 \%$ Triton X-100, and complete protease inhibitor cocktail tablets (Roche Diagnostics, Mannheim, Germany). After homogenization, samples were centrifuged at $4,000 \times g$ for $20 \mathrm{~min}$ at $4^{\circ} \mathrm{C}$. The resulting supernatants were centrifuged again until they were clear. Protein concentration was measured using the Bio-Rad DC Protein assay (Bio-Rad Laboratories, Hercules, CA, USA). Protein preparations were electrophoresed in $12.5 \%$ SDS gels under reducing conditions. Proteins were subsequently transferred to nitrocellulose (Schleicher and Schuell, Dassel, Germany) by semi-dry electroblotting for $2 \mathrm{~h}$ at $1 \mathrm{~mA} / \mathrm{cm}^{2}$ in transfer buffer containing $25 \mathrm{mM}$ Tris base, $150 \mathrm{mM}$ glycine, and $10 \%(\mathrm{v} / \mathrm{v})$ methanol. After transfer, the blot was blocked with 5\% (w/v) milk powder and $0.1 \%$ Tween-20 in PBS for $1 \mathrm{~h}$ at room temperature, and then incubated with monoclonal HCA2 (1:1000) or monoclonal HC10 (1:1000) antibodies or control mouse IgG (Sigma) overnight at $4^{\circ} \mathrm{C}$. After washing three times for $5 \mathrm{~min}$ in PBS/0.1\% Tween, the blot was incubated for $1 \mathrm{~h}$ at room temperature with horseradish peroxidase coupled goat anti-mouse $\operatorname{IgG}$ (1:4000, Santa Cruz Biotechnology, Santa Cruz, CA, USA). Prior to visualization, the blot was washed in $\mathrm{PBS} / 0.1 \%$ Tween $(3 \times 5 \mathrm{~min})$ and once more in PBS. Signals were visualized by SuperSignal West Dura enhanced luminescence substrate (Pierce Biotechnology, Rockford, IL, USA).

\section{Cell Culture and Immunoprecipitation}

HEK293T cells were transfected with linearized, fulllength Caja-G carrying a C-terminal One-STrEP-tag in pEXPR-IBA103 (IBA Technologies) using Fugene 6 (Roche, Indianapolis, IN, USA) as described by the manufacturer. Stable clones were selected with Geniticine (G418, Life Technologies, Karlsruhe, Germany) and further propagated. Protein extracts were obtained as described above. Purified Caja-G carrying a C-terminal One-STrEP-tag was obtained following manufacturer's protocol (IBA Technologies). For immunoprecipitation, $1 \mathrm{mg} / \mathrm{ml}$ of protein extract was precleared with Protein $\mathrm{G}$ Sepharose Fast Flow (GE Healthcare) for $1 \mathrm{~h}$ at $4^{\circ} \mathrm{C}$. Samples were centrifuged briefly and supernatant was incubated with either monoclonal HCA2 $\operatorname{IgG}(5 \mu \mathrm{g})$ or monoclonal $\mathrm{HC} 10 \mathrm{IgG}(5 \mu \mathrm{g})$ or without antibodies overnight on rotary platform at $4^{\circ} \mathrm{C}$, after which they were incubated with Protein G Sepharose Fast Flow (GE Healthcare) for $1 \mathrm{~h}$ at $4^{\circ} \mathrm{C}$. Samples were then centrifuged and pellets were washed three times with lysis buffer $[50 \mathrm{mM}$ Tris $/ \mathrm{HCl} \mathrm{pH} 7.4$, $150 \mathrm{mM} \mathrm{NaCl}, 1 \mathrm{mM}$ EDTA, $1 \%$ Triton-X 100 and complete protease inhibitor cocktail tablet (Roche Diagnostics, Mannheim, Germany)]. The bound proteins were eluted by boiling in Laemmli buffer and western blot was performed as described above. After transfer, the blot was blocked with $5 \%(\mathrm{w} / \mathrm{v})$ BSA (Sigma) and $0.1 \%$ Tween-20 in PBS for $1 \mathrm{~h}$ at room temperature, and then incubated with monoclonal anti-STrEP HRP-conjugated antibody (1:4000 dilution, IBA Technologies) overnight at $4{ }^{\circ} \mathrm{C}$ according to the manufacturer's instructions. After washing three times for $5 \mathrm{~min}$ in PBS $/ 0.1 \%$ Tween and once more in PBS, signals were visualized by SuperSignal West Pico enhanced luminescence substrate (Pierce Biotechnology).

\section{Electrophysiology}

Animals were terminally anesthetized with an overdose of ketamine $(50 \mathrm{mg} / \mathrm{ml})$, xylazine $(10 \mathrm{mg} / \mathrm{ml})$, and atropine $(0.1 \mathrm{mg} / \mathrm{ml})$ and intracardially perfused with ice-cold oxygenated $\left(\begin{array}{lllll}95 \% & \mathrm{O}_{2} & \text { and } & 5 \% & \mathrm{CO}_{2}\end{array}\right)$ modified artificial 
cerebrospinal fluid (ACSF) containing (in $\mathrm{mM}$ ): sucrose 220; KCl 1.9; $\mathrm{Na}_{2} \mathrm{HPO}_{4}$ 1.25; glucose $10 ; \mathrm{NaHCO}_{3} 33$; $\mathrm{MgCl}_{2} 26 ; \mathrm{CaCl}_{2} 20.5$; kynurenic acid 2; and ascorbic acid 2 (all from Sigma). Transverse hippocampal slices (300$400 \mu \mathrm{m})$ were prepared using a vibroslicer $(752 \mathrm{M}$, Campden Instruments, Loughborough, UK), transferred to the recording chamber, and allowed to recover at $33^{\circ} \mathrm{C}$ for at least $90 \mathrm{~min}$, after which they were kept at room temperature. Recordings were performed on slices placed in a submerged chamber perfused with oxygenated ACSF $\left(33^{\circ} \mathrm{C}\right.$ ) containing (in $\mathrm{mM}$ ): $\mathrm{NaCl} 124 ; \mathrm{KCl} 5 ; \mathrm{Na}_{2} \mathrm{HPO}_{4}$ 1.25; glucose 10; $\mathrm{NaHCO}_{3} 26 ; \mathrm{MgSO}_{4} 2 ; \mathrm{CaCl}_{2} 2$; and ascorbic acid 1 (all from Sigma). The recording chamber was continuously perfused with ACSF and aerated with $95 \% \mathrm{O}_{2}$ and $5 \% \mathrm{CO}_{2}(2-3 \mathrm{ml} / \mathrm{min})$. The temperature was kept at $33^{\circ} \mathrm{C}$. CA3 neurons were visually identified using infrared microscopy. The pipette solution contained (in $\mathrm{mM}$ ): potassium gluconate $135 ; \mathrm{MgCl}_{2} 2 ; \mathrm{CaCl}_{2} 0.1$; EGTA $1 ; \mathrm{Na}_{2}$ ATP 2; $\mathrm{Na}_{2}$ GTP 0.5; and HEPES 10. Spontaneous glutamatergic excitatory postsynaptic currents (sEPSCs) were recorded in the presence of $1 \mu \mathrm{M}$ strychnine and $1 \mu \mathrm{M}$ bicuculline, as described by Medrihan et al. (2008). Either control IgG or a mixture of HCA2 and HC10 antibodies at a concentration of $1.5 \mathrm{mg} / \mathrm{ml}$ each were directly applied in close proximity to neurons using glass pipettes (a schematic representation of the recording chamber set-up is provided in Supplementary figure 3). The tip size of the pipette, pressure $(0.5 \mathrm{mbar})$, and application time $(0.5 \mathrm{~s})$ were kept constant in all experiments. In addition, the distance between the pipette tip and the cells was monitored using a camera with a liquid-crystal display device and was kept constant in all experiments. Recordings of selected cells were first performed for 3 min without antibody application (control recording); the antibodies were then applied for $20 \mathrm{~min}$ at $30 \mathrm{~s}$ intervals. Patches with a serial resistance of $>10 \mathrm{M} \Omega \mathrm{a}$, membrane resistance of $<0.2 \mathrm{G} \Omega$, or leak currents of $>200 \mathrm{pA}$ were excluded. The membrane currents were filtered by a four-pole Bessel filter at a corner frequency of $2 \mathrm{kHz}$ and digitized at a sampling rate of $5 \mathrm{kHz}$ using the DigiData 1322A interface (Molecular Devices, Sunnyvale, CA, USA). Data acquisition and analysis were done using commercially available software: pClamp 9.0 (Molecular Devices), MiniAnalysis (SynaptoSoft, Decatur, GA, USA) and Prism 4 for Windows (GraphPad Software).

\section{Results}

MHCI Proteins Localize to Mossy Fibers in the Common Marmoset Hippocampus

In our previous study, we observed high levels of MHCI mRNA species throughout the hippocampus, particularly in the dentate gyrus and in the CA3 area (Rölleke et al. 2006). Specific antibodies against marmoset MHCI proteins are not available; however, their high similarity with the human homologs allowed us to use the well-characterized HCA2 and HC10 antibodies against human MHCI proteins for the detection of the marmoset MHCI proteins (Stam et al. 1990). Western blot analysis revealed that both antibodies recognized a band of approximately $45 \mathrm{kDa}$, which is the expected molecular weight of the MHCI heavy chain (Fig. 1a). Immunocytochemistry using the HCA2 antibody (Fig. 1b, f) exhibited a striking similarity with the

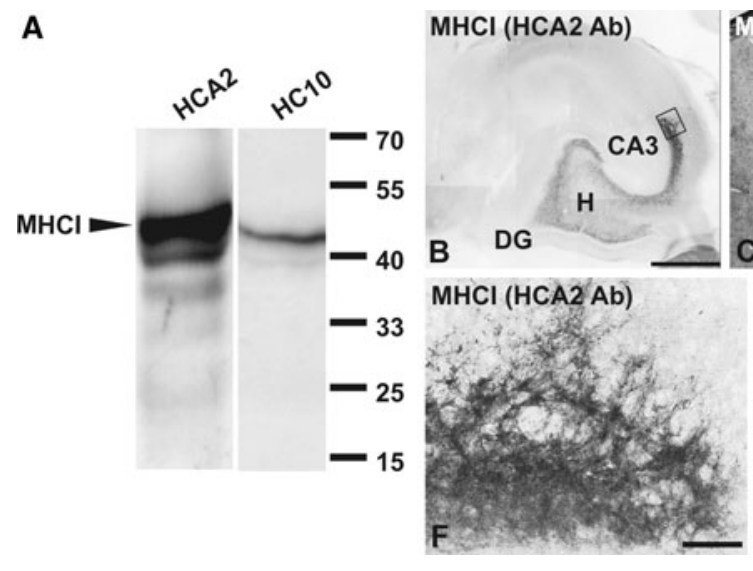

Fig. 1 MHCI protein is expressed in the mossy fiber pathway. a HCA 2 and HC10 antibodies recognized bands matching the reported molecular weight of MHCI heavy chain (45 kDa) in western blots of protein extracts from marmoset hippocampi (7-month-old animals). Protein marker molecular weights are indicated in $\mathrm{kDa}$. Halftone photographs: Both antibodies against MHCI proteins, $\mathrm{HC} 10$ and HCA2, gave similar staining patterns $(\mathbf{b}, \mathbf{c}, \mathbf{f}, \mathbf{g})$ with intense labeling

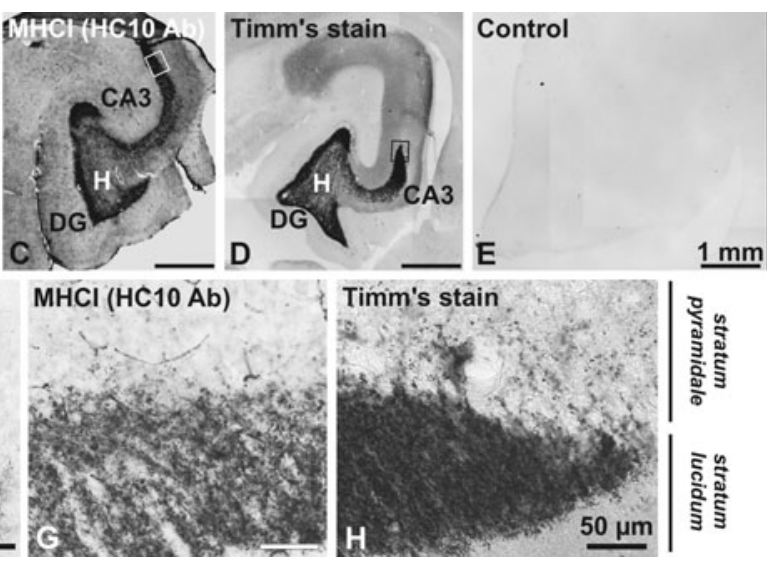

throughout the stratum lucidum (1-month-old animal). The staining patterns obtained with these antibodies were very similar to the Timm's staining (D, H) which specifically labels the mossy fiber pathway. Staining was identical in all ages examined; 1 day to 6 years old animals were used. Control antibody revealed no staining (e). Abbreviations: $A b$ antibody, $C A 3$ Cornu ammonis 3, DG dentate gyrus, $H$ hilus. Scale bars for $\mathbf{b}-\mathbf{e}$ : $1 \mathrm{~mm}$. Scale bars for $\mathbf{f}-\mathbf{h}$ : $50 \mu \mathrm{m}$ 
Timm's staining pattern, which specifically visualizes mossy fibers in the hippocampus (Fig. 1d, h; Henze et al. 2000). The strongest immunostaining was present in the stratum lucidum (CA3; Fig. 1f). Staining with the HC10 antibody showed a similar pattern (Fig. 1c, g), however, blood vessels were also stained with this antibody. Therefore, we used the HCA2 antibody in further double-labeling experiments. It is important to note that no staining of neuronal somata could be detected using these antibodies, even after the epitope retrieval step. We detected an MHCI signal solely within mossy fibers in the hippocampal formation. The distribution was identical in all ages examined (1 day to 6 years old), with slightly varying intensity. Both antibodies did not stain the CA1 and CA2 areas. Besides the hippocampal mossy fibers, MHCI could be detected in nerve terminal regions throughout the brain, mainly within hypothalamus and basal ganglia. MHCI was found to be especially enriched in the reticular part of the substantia nigra (Supplementary figure 1). No staining could be detected in the cortex or in the cerebellum (data not shown).

The anatomy of the primate hippocampus is well characterized (Seress 2007) and a number of studies on MHCI in mice have been performed in this brain region (Corriveau et al. 1998; Huh et al. 2000; Goddard et al. 2007). Therefore, we decided to focus on MHCI in the hippocampal mossy fibers in order to draw potential parallels between different findings in this and other studies more easily.

As previously mentioned, expression of MHCI on neurons has always been a highly debated and controversial topic. Thus, we first compared the expression of MHCI in the hippocampus with that of calbindin and GFAP. Calbindin is a cytoplasmic protein strongly expressed in the mossy fibers (Sequier et al. 1990; Seress et al. 1993; Cooper et al. 2008). MHCI and calbindin displayed very similar staining pattern within the hippocampus (Fig. 2a, b). Both are very likely present within the same structures in the stratum lucidum, where the mossy fibers form synapses with CA3 pyramidal neurons (Fig. 2a-c). High magnification revealed MHCI signals to be partially clustered at the mossy fibers, as previously reported in other systems (Fooksman et al. 2006), and colocalizing with calbindin (Fig. 2d, yellow structures and white arrowheads).

Glial fibrillary acidic protein (GFAP) is a well established marker of brain astrocytes (Eng et al. 2000). Double labeling experiments revealed only occasional colocalizations of GFAP and MHCI signals (Fig. 2e-h). High magnification images revealed MHCI signals dispersed between GFAP-positive astrocyte processes (Fig. 2h, white arrows).

To investigate the localization of MHCI in more detail, we performed double-labeling experiments using antibodies against Piccolo, a marker of the presynaptic active zone
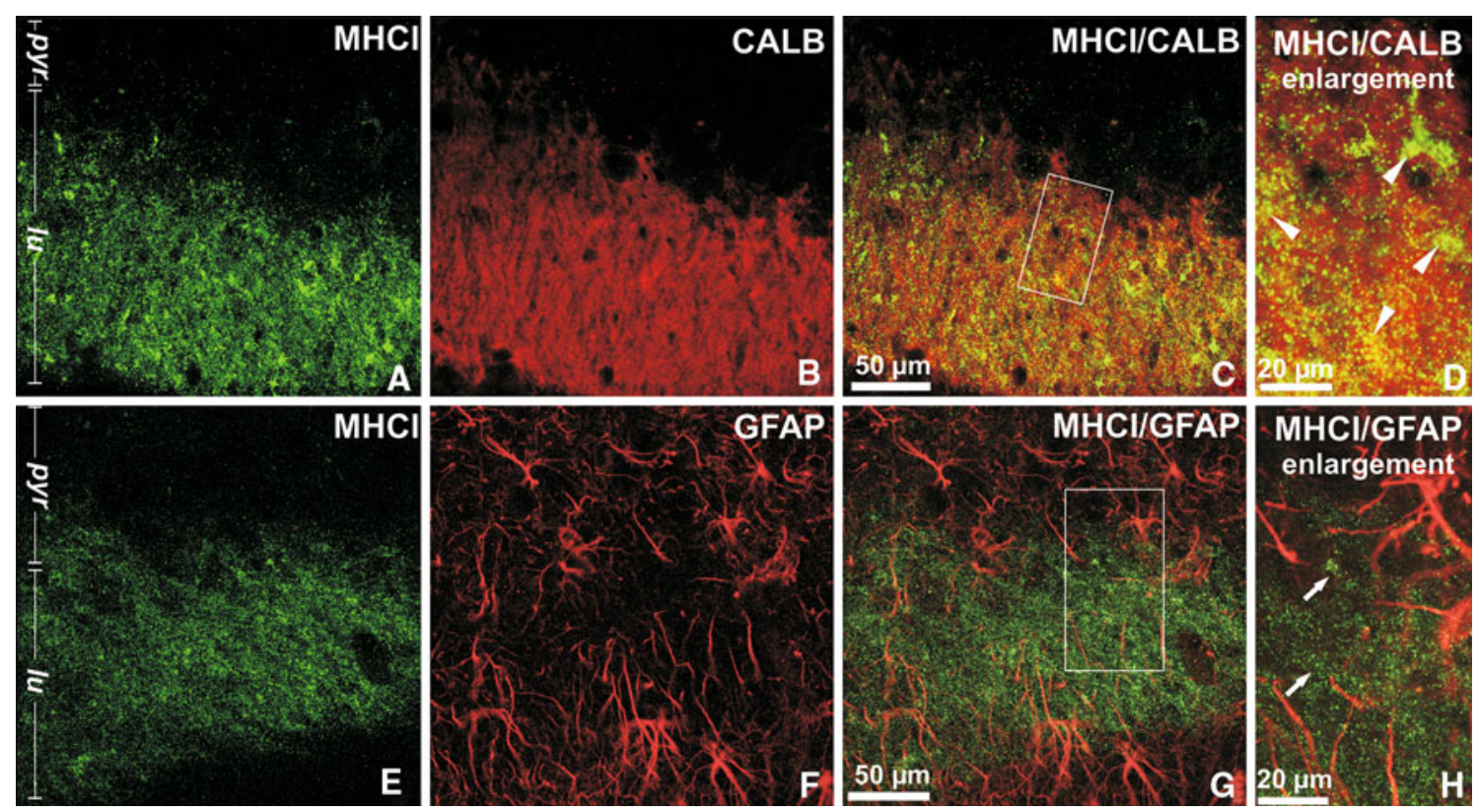

Fig. 2 MHCI protein localizes to the mossy fibers in the hippocampus. MHCI signals (green, a) significantly overlap with calbindin signals ( $\mathrm{red}, \mathbf{b}, \mathbf{c})$, the marker of mossy fibers. Almost no overlap is detected between MHCI and the astrocyte marker GFAP $(\mathbf{g})$. Higher magnification reveals MHCI signals clustered over calbindin positive nerve mossy fibers (white arrowheads, d) and dispersed between GFAP-positive astrocyte processes (white arrows, h). Animals investigated were 5 months old. Abbreviations: $l u$ stratum lucidum, pyr stratum pyramidale 
(Cases-Langhoff et al. 1996), and against postsynaptic density protein of $95 \mathrm{kDa}$ (PSD95), a marker of postsynaptic densities (Kornau et al. 1995; Qin et al. 2001; Chang et al. 2009). Piccolo is known to be situated along the presynaptic membrane in the active zone region (Dondzillo et al. 2010) and it displayed a distribution very similar to MHCI in the hippocampus (Fig. 3a, b). Like MHCI, Piccolo was enriched in the stratum lucidum (Fig. 3b). PSD95 signal was present in both pyramidal layer and stratum lucidum, as was previously reported (Fig. 3e; Qin et al. 2001). However, it was not as enriched as Piccolo and MHCI within the mossy fiber terminals in stratum lucidum. Quantification of immunofluorescence revealed that clusters of MHCI signals overlapped mainly with Piccolo signals, whereas very little overlap was detected with PSD95 (Fig. 3i). High magnification images revealed significant colocalization of MHCI and Piccolo signals (Fig. 3g; yellow spots and white arrowheads). Clusters of MHCI and PSD95 signals were also found to partially overlap (Fig. 3h, white arrowheads). This is not surprising since PSD95, as a component of the postsynaptic densities (Cho et al. 1992; Hunt et al. 1996), is located in direct apposition to the presynaptic terminal membrane, and these two structures cannot be clearly distinguished from each other with standard confocal microscopy. This finding was similar to what has been observed previously with synapsin-I and PSD95 in cerebellum (Castejon et al. 2004) and colocalization of presynaptic proteins (such as synapsin-I)
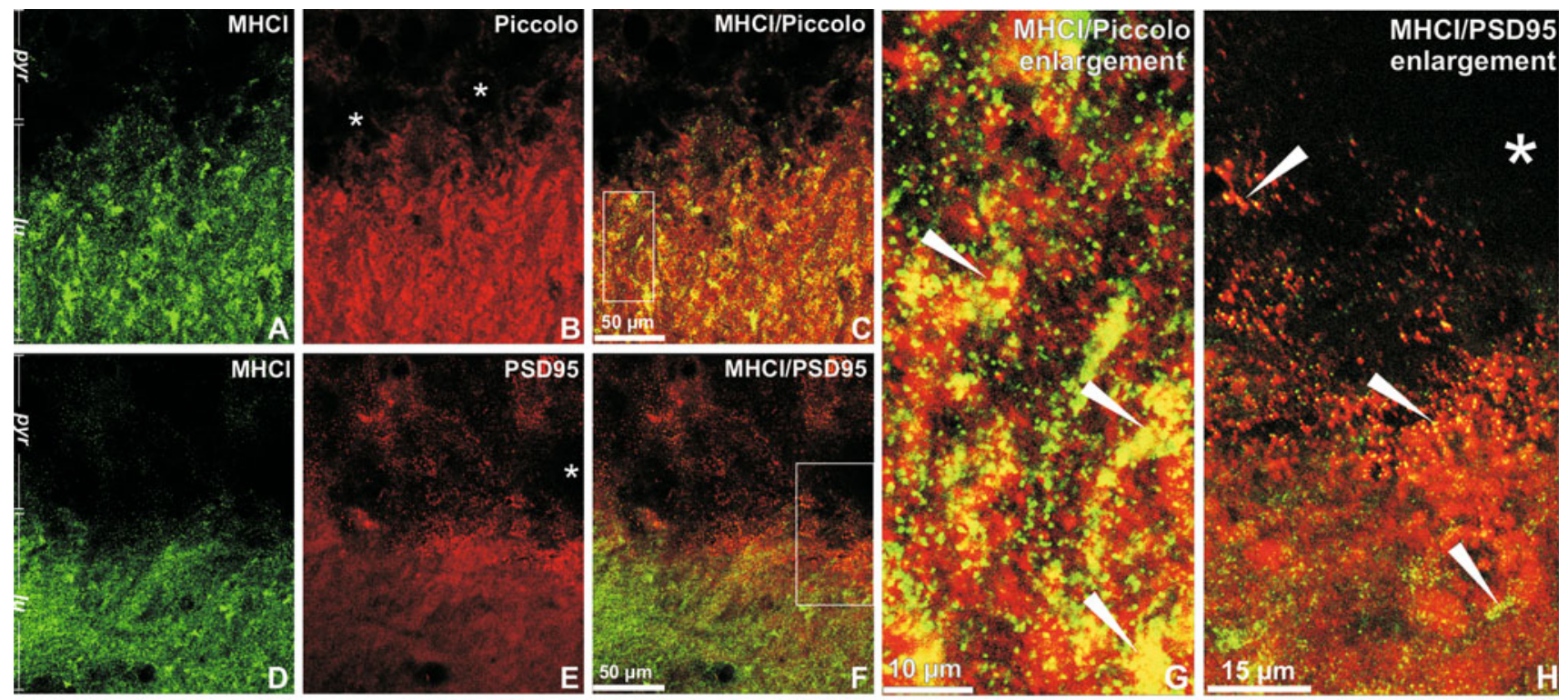

I

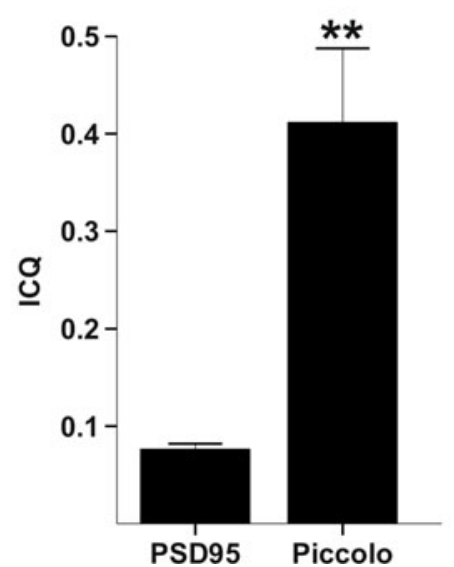

Fig. 3 MHCI protein is localized on the presynaptic side of the mossy fiber-CA3 synapse. MHCI signals (green, a) significantly overlap with those of Piccolo ( red, $\mathbf{b}, \mathbf{c}$ ), marker of the presynaptic active zone. Very little overlap is detected between MHCI (d) and the postsynaptic marker PSD95 (e, f). Higher magnification reveals MHCI signal clustered over Piccolo-positive regions (white arrowheads, $\mathbf{g}$ ). Some PSD95 signals emerge close to MHCI signals (white arrowheads, $\mathbf{h})$. Quantification of immunofluorescence revealed that MHCI is mainly associated with the presynaptic side of the mossy fiber-CA3 synapses (i). Animals used were 7 months old. Data represent means $\pm \mathrm{SEM}, N=3$. Significant differences between groups as determined by Student's $t$-test: $* * P<0.01$. Abbreviations: $l u$ stratum lucidum, pyr stratum pyramidale; * CA3 pyramidal neuron, ICQ intensity correlation quotient 
with PSD95 has previously been reported (Castejon et al. 2004; Graf et al. 2004; Cheng et al. 2008). These data suggest that MHCI is mainly localized presynaptically, at or very near the synapses themselves.

\section{MHCI Proteins are Mainly Present in the Giant Mossy Fiber Terminals}

In the hippocampus, mossy fibers form specialized "giant" terminals that innervate the apical dendrites of CA3 pyramidal neurons. Moreover, small terminals innervate the interneurons present in the hilus and in the stratum lucidum (Henze et al. 2000; Nicoll and Schmitz 2005). The vesicular glutamate transporter 1 (VGlut1) mainly localizes to large mossy fiber terminals (Bellocchio et al. 1998; Herzog et al. 2001; Cooper et al. 2008). In contrast, the vesicular glutamate transporter 2 (VGlut2) is present in small terminals, which are VGlut1 negative and make contacts with the inhibitory interneurons (Herzog et al. 2006). To further characterize the localization of MHCI protein in mossy fibers, we assessed its colocalization with VGlut1 and VGlut2. MHCI proteins predominantly colocalized with VGlut1-immunopositive clusters and the two immunofluorescent signals intensively overlapped (Fig. 4c, d). MHCI signals were clustered over presumptive VGlut1-positive mossy fiber terminals (mft, Fig. 4d). In accordance with previous findings (Bellocchio et al. 1998; Herzog et al. 2006; Cooper et al. 2008), VGlut1 was found to be very abundant in the stratum lucidum and sparse in the pyramidal cell layer, while VGlut2 signals appeared predominantly as immunopositive puncta within the pyramidal layer with a very sparse distribution within stratum lucidum (Fig. 4f). Very little colocalization of MHCI with VGlut2 signals was observed (Fig. 4h). Quantification of immunofluorescence revealed a stronger correlation between MHCI and VGlut1 than between MHCI and VGlut2, which (together with image analysis) suggested that the MHCI proteins are mainly localized to the large mossy fiber terminals that innervate CA3 pyramidal neurons (that are in general VGlut2 negative). Furthermore, MHCI is mainly absent from VGAT-positive interneuron terminals within the hippocampus (Supplementary figure 3; Cooper et al. 2008), which additionally suggests its localization to the giant mossy fiber terminals.

Neuronal MHCI Proteins are Involved in Excitatory Transmission at Mossy Fiber-CA3 Synapses in the Marmoset Hippocampus

To elucidate the potential functions of neuronal MHCI proteins, we performed whole-cell patch-clamp recordings of CA3 neurons in acute slices of the marmoset hippocampus. As the gene knockdown technology in nonhuman primates is still in its early stages (Sasaki et al. 2009), we decided to interfere with the cell-surface expression of MHCI proteins via the application of HCA2 and HC10 antibodies. Although $\mathrm{HC} 10$ and $\mathrm{HCA} 2$ were raised against denatured MHCI heavy chains, we specifically immunoprecipitated a native marmoset MHCI molecule from cells transfected with a tagged marmoset MHCI construct using both antibodies (Fig. 5).

As we have localized MHCI proteins to the VGlut1positive mossy fiber terminals in the marmoset hippocampus, we investigated the changes in spontaneous excitatory postsynaptic currents (sEPSCs) exclusively in CA3 neurons. Application of HC10 and HCA2 antibodies significantly decreased the frequency of sEPSCs. The normalized mean frequency of sEPSCs decreased by $28.75 \%( \pm 10.28 \%), 5 \mathrm{~min}$ after the application of the antibodies compared with the baseline level (100\%). Twenty minutes after antibody application, the normalized mean frequency decreased by $39.23 \%( \pm 9.27 \%)$ [Fig. $6 \mathrm{a}$ (right panel), b]. In addition, application of these antibodies also transiently increased the normalized amplitude of sEPSCs by $22.4 \%( \pm 10.62 \%)$ after $10 \mathrm{~min}$ (Fig. 6a, c). Application of the control IgG had no significant effect on either the frequency or the amplitude of sEPSCs [Fig. 6a (left panel), b, c]. These data suggest that MHCI proteins have a specific function in maintenance and regulation of basal neurotransmission at the primate mossy fiber-CA3 synapses.

\section{Discussion}

Expression of MHC class I molecules in neurons of the CNS has been debated over the years. The dogma of the immune privilege of the brain supports the notion that neurons normally do not express MHCI proteins, and that neuronal MHCI molecules can only be observed after induction by cytokines (Neumann et al. 1995). However, several recent studies performed in rodents provide experimental evidence emphasizing an important role for MHCI molecules in the modulation of synaptic plasticity and in the proper development of brain circuitry in the normal, noninjured brain (Corriveau et al. 1998; Huh et al. 2000; Goddard et al. 2007).

Although there are some differences in the structure and function of molecules in the MHCI family between rodents and primates, previous results reported by our group suggested a relatively conserved expression pattern of a subset of MHCI molecules in the brains of rodents and nonhuman primates (Rölleke et al. 2006). MHCI molecules are very numerous and are usually divided into classical and nonclassical MHCI molecules. Classical MHCI molecules are in general associated with immune responses, while the 

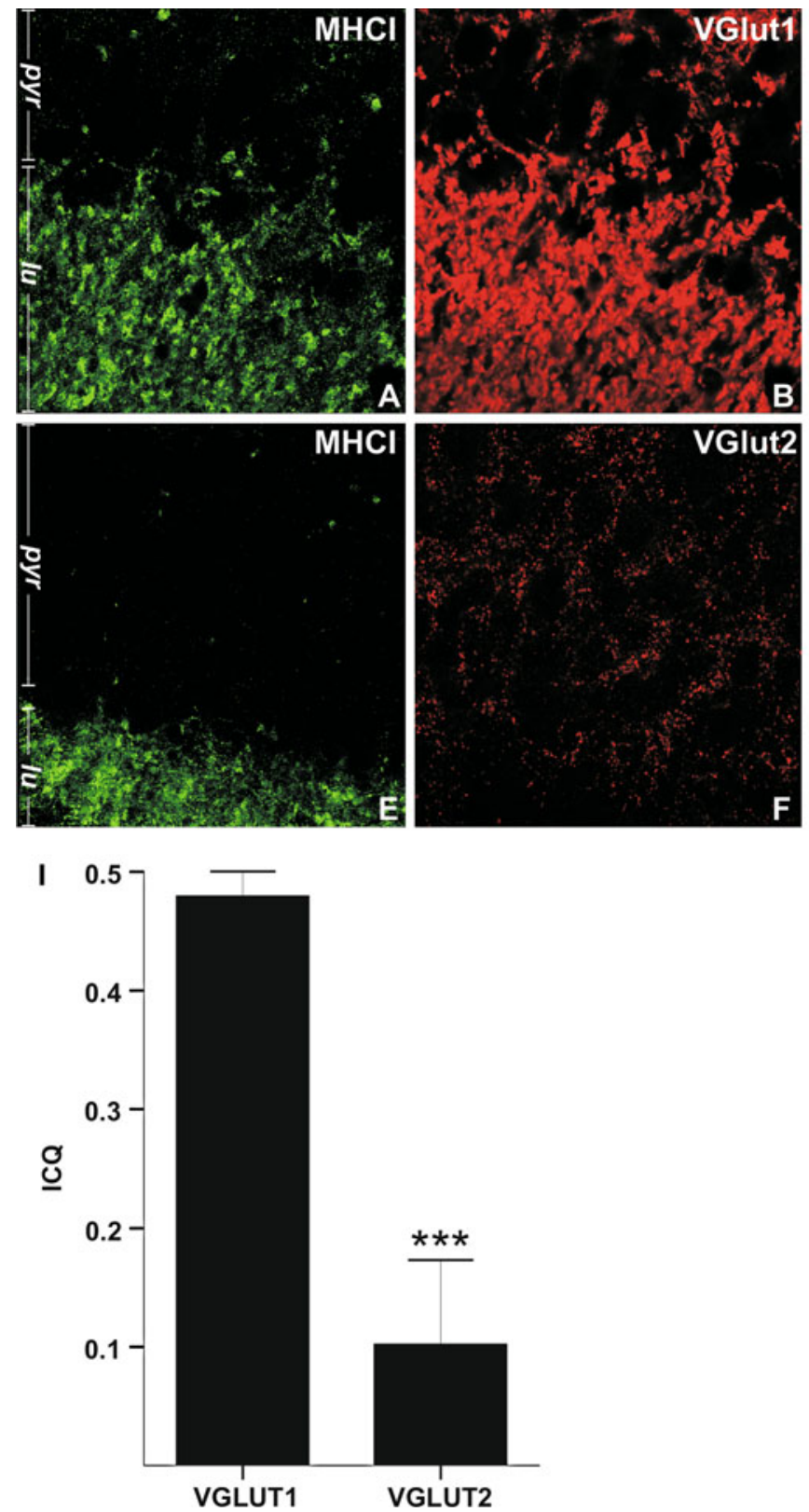

Fig. 4 MHCI protein is present on large mossy fiber boutons. MHCI (a) is predominantly localized on VGlut1 positive large mossy fiber boutons (c, white arrowheads in d). Very little overlap is seen between MHCI (e) and VGlut2 (f) which labels small mossy fiber boutons and filopodial extensions (g, white arrowheads in $\mathbf{h})$. Quantification of the immunofluorescence revealed significant difference between overlapping signals of MHCI with VGlut1 and VGlut2,

non-classical MHCIs have more elusive roles, especially outside of the immune system (Arosa et al. 2007). In rodents, classical MHCI genes have recently been implicated in synaptic refinement and the maintenance of synaptic plasticity in cerebellum and visual system (Datwani et al. 2009; McConnell et al. 2009). The non-classical
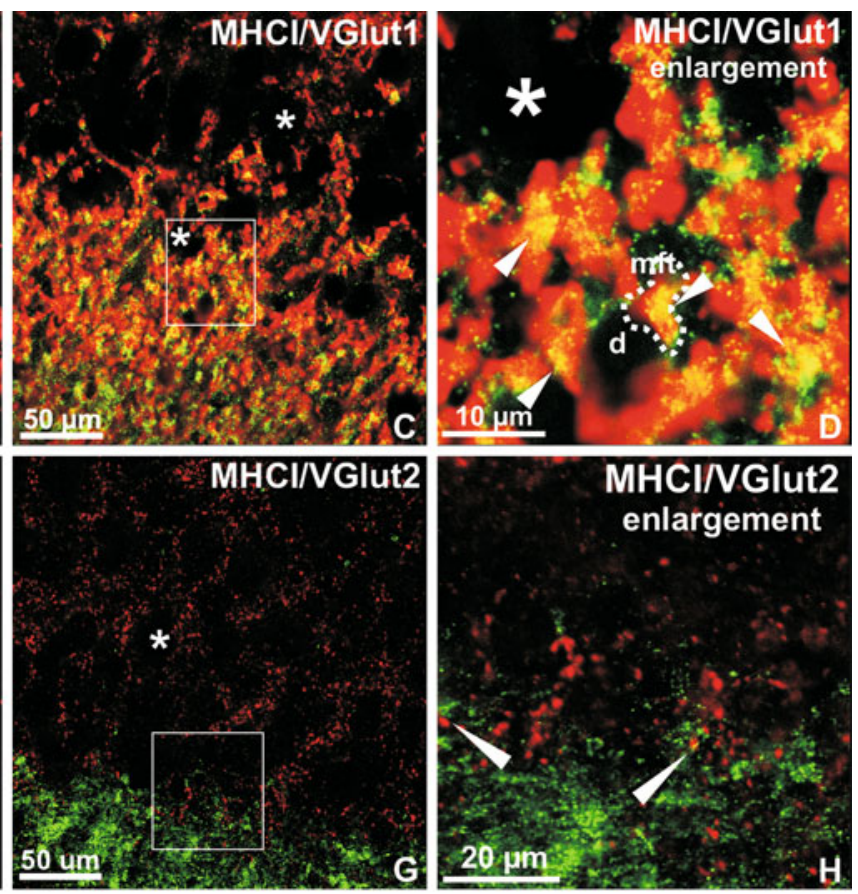

respectively (i). Animals used were 7 months old. Data represent means $\pm \mathrm{SEM}, N=3$. Significant differences between groups as determined by Student's $t$-test: $* * * P<0.001$. Abbreviations: $l u$ stratum lucidum, pyr stratum pyramidale, $m f t$ mossy fiber terminal, $d$ dendrite; * CA3 pyramidal neuron, ICQ intensity correlation quotient

MHCI subset is believed to be involved in the proper development of the vomeronasal organ in mice (Ishii and Mombaerts 2008). We believe that the subset previously detected by us in the marmoset brain belongs to the nonclassical MHCI molecules (Rölleke et al. 2006). In this study, however, another subset of MHCI proteins displayed 


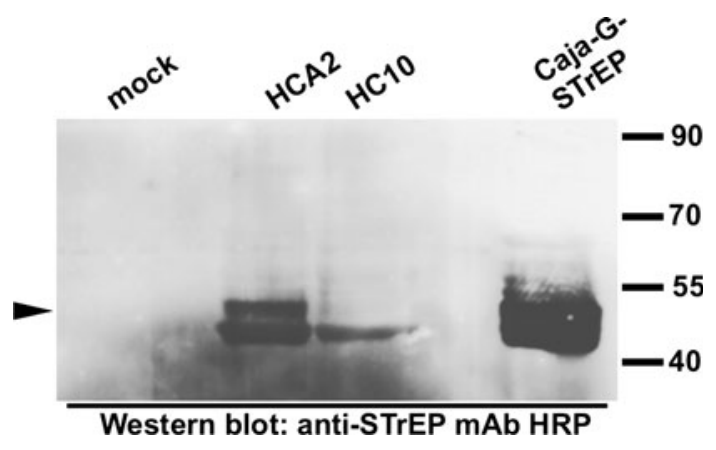

Fig. 5 Antibodies HCA2 and $\mathrm{HC} 10$ recognize the native marmoset MHCI protein. HEK293T cells were transfected with the marmoset MHCI construct carrying One-STrEP-tag. Protein extracts were immunoprecipitated with $\mathrm{HCA} 2$ and $\mathrm{HC} 10$ antibodies under non-denaturing conditions and analyzed with Western blots using a HRP-conjugated antibody against the STrEP-tag. Both antibodies precipitated One-STrEP-tagged marmoset MHCI; mock (beads only) revealed no signals. Purified marmoset MHCI with One-STrEP-tag (Caja-G-STrEP) was used as a positive control. Lanes between mock, immunoprecipitates and the purified Caja-G protein were kept empty in order to avoid sample spillover and lane contamination. Protein marker molecular weights are indicated in $\mathrm{kDa}$
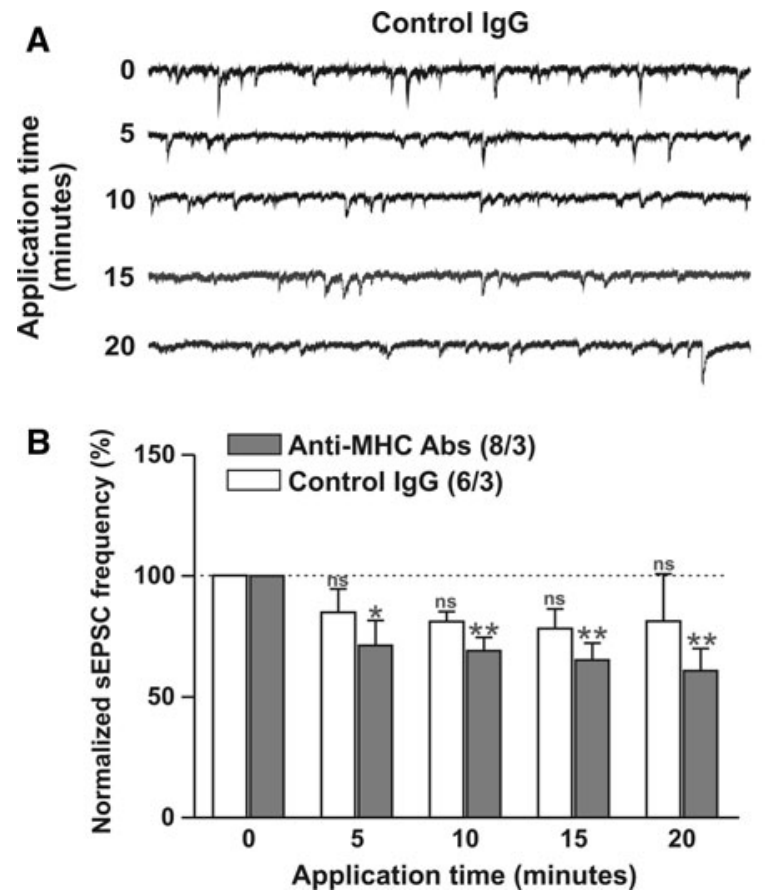

Fig. 6 Application of antibodies against MHC class I proteins to marmoset hippocampal slices decreases frequency of sEPSCs. a Representative recordings of pharmacologically isolated spontaneous excitatory postsynaptic currents (sEPSC) from CA3 neurons during the experiment. Recordings with the application of control immunoglobulins are on the left side, and recordings with the application of antibodies against MHCI proteins are on the right side. b Averaged frequency of spontaneous ESPCs significantly decreased after $10 \mathrm{~min}$ of antibody application. Normalized mean frequency of sEPSCs decreased $28.75 \%( \pm 10.28) 5$ minutes after the application of the antibodies and continued to decrease down to $39.23 \%( \pm 9.270)$ of baseline level. $\mathbf{c}$ In addition, application of antibodies also transiently distinct and so far unreported expression patterns and properties.

Staining with antibodies that target the heavy-chain subunit of the classical MHCI molecules revealed a strong MHCI expression confined to the mossy fibers in the hippocampal formation. Both antibodies used here targeted an epitope situated in the most polymorphic region of the MHCI molecules; therefore, these antibodies are specific for only a small portion of MHCI proteins. In humans, these antibodies recognize the classical MHCI molecules and (in case of the HCA2 antibody) some non-classical MHCI (Stam et al. 1986, 1990; Seitz et al. 1998; Gauster et al. 2007). The marmoset MHCI genes are yet to be characterized, but based on what has previously been published on this topic (Cadavid et al. 1997) and on the data available for the epitopes of these antibodies (Stam et al. 1986, 1990; Seitz et al. 1998; Gauster et al. 2007), we believe that the MHCI detected in this study belongs to the classical subset. Both antibodies recognized bands of the appropriate size on western blots and, with respect to the
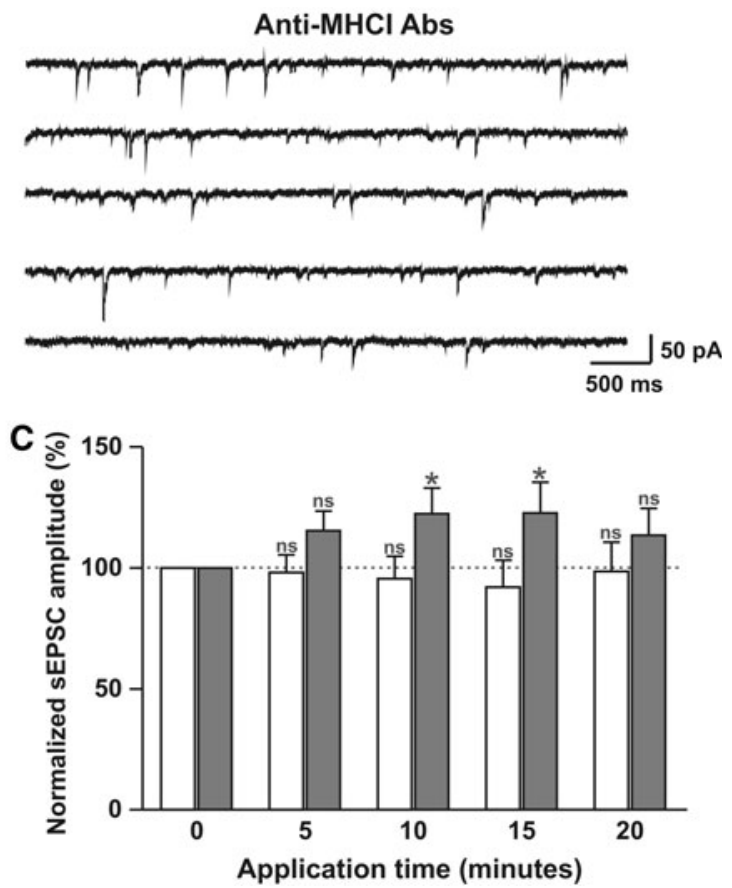

increased the normalized amplitude of sEPSCs by $22.4 \%( \pm 10.62)$ compared to baseline level after $10 \mathrm{~min}$. Application of control IgG had no significant effect on either the frequency or the amplitude of sEPSCs. Animals used were 2-5 years old and no significant differences in both frequency and amplitude were observed with regard to the age of animals. Data represent means \pm SEM. Numbers in parentheses indicate the number of neurons/marmosets tested for each experimental group. Distribution of data was tested with Kolmogorov-Smirnov test. Significant differences between groups as determined by One-way ANOVA with repeated measures with Dunnet's post hoc-test using initial recording without antibody application as control: * $P<0.05, * * P<0.01$ 
neuronal staining, yielded almost identical staining patterns in immunocytochemical experiments, which supports their specificity. In addition, both $\mathrm{HCA} 2$ and $\mathrm{HC} 10$ immunoprecipitated a native, classical marmoset $\mathrm{MHCI}$ protein, Caja-G.

Our double-labeling experiments suggest that MHCI proteins are localized on the nerve terminals, and not on glial processes. Furthermore, our experiments suggest that the MHCI proteins targeted here are presynaptic and primarily associated with the large mossy fiber boutons, which provide the main excitatory input to CA3 pyramidal neurons. Thus, the present results from marmosets differ from previous findings in mice, in which a postsynaptic role of MHCI proteins was discussed (Goddard et al. 2007). In accordance with the presynaptic localization detected here, MHCI proteins have recently been reported in the nerve terminals at the neuromuscular junction in mice (Thams et al. 2009). The fact that no MHCI proteins were detected in the hippocampal mossy fibers of mice may be due to a lack of suitable antibodies against mouse MHCI proteins. However, it is also possible that MHCI expression in mossy fibers is a marmoset (or primate)-specific trait. As previously mentioned, the non-classical MHCI molecules exhibit expression patterns that are very similar to the one detected in rodents (Corriveau et al. 1998; Rölleke et al. 2006). Given the high evolution rate of MHCI molecules (Kumanovics et al. 2003), it is likely that a fraction of classical MHCI proteins developed a new function and localization. A detailed comparative study between rodents and primates using equivalent tools is needed to elucidate this issue. However, the results obtained using whole-cell patch-clamp recordings in marmoset $\mathrm{CA} 3$ neurons suggest the presence of interspecies differences.

Electrophysiology in nonhuman primates is not commonly employed given that mouse models are usually readily available. Furthermore, ethical standards regarding the use of nonhuman primates in neurobiological research limit the number of primates as experimental animals, and the preparation of acute brain slices from primates is more arduous compared to the preparation of rodent acute brain slices. However, the opposing results with respect to the localization of MHCI molecules in the hippocampus of mice and marmosets did not allow us to use mice for electrophysiological experiments. In addition, we felt it was important to elucidate the function of neuronal MHCI in the primate hippocampus precisely because of the pronounced interspecies differences in their localization within the hippocampal formation. As MHCI knockout marmosets or specific neuronal MHCI antagonists are not currently available, we used antibodies to block MHCI on the surface of mossy fiber terminals. The effects observed were not an artifact of the antibody application, as there was no significant effect of the application of control immunoglobulins in the same concentration (Fig. 6). Previously published data suggest that the use of antibodies that block cell-surface receptors is an adequate method for investigating the function of proteins for which knockout models or antagonists are not available (Bufler et al. 1996; Saghatelyan et al. 2000; Mameli et al. 2005).

In our experiments, the normalized mean frequency of sEPSCs was significantly reduced after application of the blocking antibodies and this effect increased proportionally with the duration of the incubation. Furthermore, we observed a small, but significant transient increase in the amplitude of sEPSCs (Fig. 6). These results did not match previous observations in rodents where it has been found that the lack of surface MHCI expression leads to an increase in mEPSCs (miniature EPSCs) frequency of hippocampal neurons (Goddard et al. 2007). As already mentioned, it is possible that the MHCI molecules targeted in the present study belong to a subset of MHCIs that has not yet been detected in mice because of the unavailability of proper antibodies. However, the mice used in the previous studies lacked expression of the majority of, if not all, MHCI genes (Goddard et al. 2007). On the other hand, we recorded sEPSCs here, not mEPSCs (as in the study in mice), which may also account for some of the differences observed.

It is obvious that evolution provided MHCI molecules with a number of diverse functions, both immune and nonimmune (Fishman et al. 2004). A potential explanation for the function of MHCI at the mossy fiber-CA3 synapses arises when previous studies on MHCI are taken into consideration. The mossy fiber-CA3 synapse displays a number of peculiarities when compared with the majority of CNS synapses. For instance, it is characterized by a low basal neurotransmission, which is maintained via the activation of receptors that have inhibitory effects on synaptic transmission (Nicoll and Schmitz 2005). Given that the best characterized nonimmune function of MHCI molecules is the regulation of trafficking and internalization of various receptors (Arosa et al. 2007), we hypothesize that the function of neuronal MHCI proteins (consistent with the results obtained here) is the proper internalization of one or several of those receptors. One may speculate that blocking the interaction of MHCI molecules with their receptors by application of anti-MHCI antibodies would prolong inhibitory signaling, thus reducing the frequency of sEPSCs. This does not fully explain the transient increase in the amplitude of sEPSCs: although changes in the amplitude of the spontaneous currents usually imply a defect in the postsynapse, sometimes they may also be a reflection of a presynaptic mechanism (Sharma and Viijayaraghavan 2003). Further electrophysiological analyses are required to dissect the action of MHCI proteins in synaptic transmission. The identification of interacting 
partner(s) and signaling mechanisms are crucial to the elucidation of the function of neuronal MHCI molecules.

In conclusion, the present study contributes to the growing body of evidence that MHCI molecules are involved in synaptic plasticity processes in the CNS. It remains unclear whether the presynaptic and mossy fiberspecific expression of MHCI molecules observed in this study is marmoset specific, or whether it is a characteristic of all nonhuman primates. A number of proteins display differential localization in rodents and primates, which is usually taken as a possible basis for the evolution of the primate brain with respect to cognitive functions. Furthermore, a concept of MHCI signaling in neurons has very important implications, particularly when considering autoimmune diseases that affect the CNS and various diseases genetically linked to the MHC, such as autism (Belmonte et al. 2004). With this in mind, further research is required to elucidate the exact mechanisms of the action of nonhuman primate neuronal MHCI, particularly regarding interspecies expression differences.

Acknowledgments The authors wish to thank T. Meyer-Burhenne and S. Leineweber for expert animal care, A. Hoffmann, J. Krenzek, S. Kosin, A. Heutz, and A. Zank for technical assistance, Dr. B. Czéh for assistance with the Timm's staining protocol, Dr. L. Medrihan for help establishing the patch clamp recording techniques and Dr. B. Cooper for invaluable advice regarding synaptic markers. AR was supported by an EC fellowship for Neuroscience Early Stage Research Training (NEUREST) and was a student of the MSc/PhD Molecular Biology Graduate Program in Göttingen, Germany. This work was supported by EU grant NEST-28594 and the SFB 449, TP B6.

Open Access This article is distributed under the terms of the Creative Commons Attribution Noncommercial License which permits any noncommercial use, distribution, and reproduction in any medium, provided the original author(s) and source are credited.

\section{References}

Aarli JA (1983) The immune system and the nervous system. J Neurol 229:137-154

Abramoff MD, Magelhaes PJ, Ram SJ (2004) Image processing with ImageJ. Biophotonics Int 11:36-42

Arosa FA, Santos SG, Powis SJ (2007) Open conformers: the hidden face of MHC-I molecules. Trends Immunol 28:115-123

Bellocchio EE, Hu H, Pohorilee A, Chan J, Pickerl VM, Edwards RH (1998) The localization of the brain specific inorganic phosphate transporter suggests a specific presynaptic role in glutamatergic transmission. J Neurosci 18:8848-8849

Belmonte MK, Allen G, Beckel-Mitchener A, Boulanger LM, Carper RA, Webb SJ (2004) Autism and abnormal development of brain connectivity. J Neurosci 24:9228-9231

Bufler J, Kahlert S, Tzartos S, Toyka KV, Maelicke A, Franke C (1996) Activation and blockade of mouse muscle nicotinic channels by antibodies directed against the binding site of the acetylcholine receptor. J Physiol 492:107-114
Cadavid LF, Shufflebotham C, Ruiz FJ, Yeager M, Hughes AL, Watkins DI (1997) Evolutionary instability of the major histocompatibility complex class I loci in New World primates. Proc Natl Acad Sci USA 94:14536-14541

Cases-Langhoff C, Voss B, Garner AM, Appeltauer U, Takei K, Kindler S, Veh RW, De Camilli P, Gundelfinger ED, Garner CC (1996) Piccolo, a novel $420 \mathrm{kDa}$ protein associated with the presynaptic cytomatrix. Eur J Cell Biol 69:214-223

Castejon OJ, Fuller L, Dailey ME (2004) Localization of synapsin-I and PSD-95 in developing postnatal rat cerebellar cortex. Brain Res Dev Brain Res 151:25-32

Chang LR, Liu JP, Zhang N, Wang YJ, Gao XL, Wu Y (2009) Different expression of NR2B and PSD-95 in rat hippocampal subregions during postnatal development. Microsc Res Tech 72:517-524

Cheng C, Gao S, Zhao J, Niu S, Chen M, Li X, Qin J, Shi S, Guo Z, Shen A (2008) Spatiotemporal patterns of postsynaptic density (PSD)-95 expression after rat spinal cord injury. Neuropathol Appl Neurobiol 34:340-356

Cho K-O, Hunt CA, Kennedy MB (1992) The rat brain postsynaptic density fraction contains a homolog of the Drosophila disc-large tumor suppressor protein. Neuron 9:929-942

Cooper B, Werner HB, Flügge G (2008) Glycoprotein M6a is present in glutamatergic axons in adult rat forebrain and cerebellum. Brain Res 1197:1-12

Corriveau RA, Huh GS, Shatz CJ (1998) Regulation of class I MHC gene expression in the developing and mature CNS by neural activity. Neuron 21:505-520

Cresswell P, Ackerman AL, Giodini A, Peaper DR, Wearsch PA (2005) Mechanisms of MHC class I-restricted antigen processing and cross-presentation. Immunol Rev 207:145-157

Datwani A, McConnell MJ, Kanold PO, Micheva KD, Busse B, Shamloo M, Smith SJ, Shatz CJ (2009) Classical MHCI molecules regulate retinogeniculate refinement and limit ocular dominance plasticity. Neuron 64:463-470

Dondzillo A, Sätzler K, Horstmann H, Altrock WD, Gundelfinger ED, Kuner T (2010) Targeted three-dimensional immunohistochemistry reveals localization of presynaptic proteins Bassoon and Piccolo in the rat calyx of Held before and after the onset of hearing. J Comp Neurol 518:1008-1029

Eng LF, Ghirnikar RS, Lee YL (2000) Glial fibrillary acidic protein: GFAP-thirty-one years (1969-2000). Neurochem Res 25:14391451

Fishman D, Elhyany S, Segal S (2004) Non-immune functions of MHC class I glycoproteins in normal and malignant cells. Folia Biol 50:35-42

Fooksman DR, Gronvall GK, Tang Q, Edidin M (2006) Clustering class I MHC modulates sensitivity of $\mathrm{T}$ cell recognition. J Immunol 176:6673-6680

Gauster M, Blaschitz A, Dohr G (2007) Monoclonal antibody HC10 does not bind HLA-G. Rheumatology 46:892-893

Goddard CA, Butts DA, Shatz CJ (2007) Regulation of CNS synapses by neuronal MHC class I. Proc Natl Acad Sci USA 104:68286833

Graf ER, Zhang XZ, Jin S-X, Linhoff MW, Craig AM (2004) Neurexins induce differentiation of GABA and glutamate postsynaptic specializations via neuroligins. Cell 119:1013-1026

Henze DA, Urban NN, Barrionuevo G (2000) The multifarious hippocampal mossy fiber pathway: a review. Neuroscience 98:407-427

Herzog E, Bellenchi GC, Gras C, Bernard V, Ravassard P, Bedet C, Gasnier B, Giros B, ElMestikawy S (2001) The existence of a second vesicular glutamate transporter specifies subpopulations of glutamatergic neurons. J Neurosci 21:RC181:1-6

Herzog E, Takamori S, Jahn R, Brose N, Wojcik SM (2006) Synaptic and vesicular colocalization of the glutamate transporters 
VGLUT1 and VGLUT2 in the mouse hippocampus. J Neurochem 993:1011-1018

Huh GS, Boulanger LM, Du H, Riquelme PA, Brotz TM, Shatz CJ (2000) Functional requirement for class I MHC in CNS development and plasticity. Science 290:2155-2159

Hunt CA, Schenker LJ, Kennedy MB (1996) PSD-95 is associated with the postsynaptic density and not with the presynaptic membrane at forebrain synapses. J Neurosci 16:1380-1388

Ishii T, Mombaerts P (2008) Expression of nonclassical class I major histocompatibility genes defines a tripartite organization of the mouse vomeronasal system. J Neurosci 28:2332-2341

Kornau HC, Schenker LT, Kennedy MB, Seeburg PH (1995) Domain interaction between NMDA receptor subunits and the postsynaptic density protein PSD-95. Science 269:1737-1740

Kumanovics A, Takada T, Lindahl KF (2003) Genomic organization of the mammalian MHC. Annu Rev Immunol 21:629-657

Li Q, Lau A, Morris TJ, Guo L, Fordyce CB, Stanley EF (2004) A syntaxin 1 , Galpha(o), and $\mathrm{N}$-type calcium channel complex at a presynaptic nerve terminal: analysis by quantitative immunocolocalization. J Neurosci 24:4070-4081

Mameli M, Carta M, Partridge LD, Valenzuela CF (2005) Neurosteroid-induced plasticity of immature synapses via retrograde modulation of presynaptic NMDA receptors. J Neurosci 25: 2285-2294

McConnell MJ, Huang YH, Datwani A, Shatz CJ (2009) H2-K(b) and $\mathrm{H} 2-\mathrm{D}(\mathrm{b})$ regulate cerebellar long-term depression and limit motor learning. Proc Natl Acad Sci USA 106:6784-6789

Medrihan L, Tantalaki E, Aramuni G, Sargsyan V, Dudanova I, Missler M, Zhang W (2008) Early defects of GABAergic synapses in the brain stem of a MeCP2 mouse model of Rett syndrome. J Neurophysiol 99:112-121

Neumann H, Cavalie A, Jenne DE, Wekerle H (1995) Induction of MHC class I genes in neurons. Science 269:549-552

Nicoll RA, Schmitz D (2005) Synaptic plasticity at hippocampal mossy fibre synapses. Nat Rev Neurosci 6:863-876

Qin L, Marrs GS, McKim R, Dailey ME (2001) Hippocampal mossy fibers induce assembly and clustering of PSD95-containing postsynaptic densities independent of glutamate receptor activation. J Comp Neurol 440:284-298

Rölleke U, Flügge G, Plehm S, Schlumbohm C, Armstrong VW, Dressel R, Uchanska-Ziegler B, Ziegler A, Fuchs E, Czeh B, Walter L (2006) Differential expression of major histocompatibility complex class I molecules in the brain of a New World monkey, the common marmoset (Callithrix jacchus). J Neuroimmunol 176:39-50

Saghatelyan AK, Gorissen S, Albert M, Hertlein B, Schachner M, Dityatev A (2000) The extracellular matrix molecule tenascin-R and its HNK-1 carbohydrate modulate perisomatic inhibition and long-term potentiation in the CA1 region of the hippocampus. Eur J Neurosci 12:3331-3342

Sasaki E, Suemizu H, Shimada A, Hanazawa K, Oiwa R, Kamioka M, Tomioka I, Sotomaru Y, Hirakawa R, Eto T, Shiozawa S, Maeda T, Ito M, Ito R, Kito C, Yagihashi C, Kawai K, Miyoshi H, Tanioka Y, Tamaoki N, Habu S, Okano H, Nomura T (2009) Generation of transgenic non-human primates with germline transmission. Nature 459:523-527

Seitz C, Uchanska-Ziegler B, Zank A, Ziegler A (1998) The monoclonal antibody HCA2 recognises a broadly shared epitope on selected classical as well as several non-classical HLA class I molecules. Mol Immunol 35:819-827

Sequier JM, Hunziker W, Andressen C, Celio MR (1990) Calbindin D-28 k protein and mRNA localization in the rat brain. Eur $\mathrm{J}$ Neurosci 2:1118-1126

Seress L (2007) Comparative anatomy of the hippocampal dentate gyrus in adult and developing rodents, non-human primates and humans. Prog Brain Res 163:23-41

Seress L, Gulyas AI, Ferrer I, Tunon T, Soriano E, Freund TF (1993) Distribution, morphological features, and synaptic connections of parvalbumin- and calbindin D28k-immunoreactive neurons in the human hippocampal formation. J Comp Neurol 337:208-230

Seress L, Abraham H, Paleszter M, Gallyas F (2001) Granule cells are the main source of excitatory input to a subpopulation of GABAergic hippocampal neurons as revealed by electron microscopic double staining for zinc histochemistry and parvalbumin immunocytochemistry. Exp Brain Res 136:456-462

Sharma G, Viijayaraghavan S (2003) Modulation of presynaptic store calcium induces release of glutamate and postsynaptic firing. Neuron 38:929-939

Solheim JC (1999) Class I MHC molecules: assembly and antigen presentation. Immunol Rev 172:11-19

Stam NJ, Spits H, Ploegh HL (1986) Monoclonal antibodies raised against denatured HLA-B locus heavy chains permit biochemical characterization of certain HLA-C locus products. J Immunol 137:2299-2306

Stam NJ, Vroom TM, Peters PJ, Pastoors EB, Ploegh HL (1990) HLA-A- and HLA-B-specific monoclonal antibodies reactive with free heavy chains in western blots, in formalin-fixed, paraffin-embedded tissue sections and in cryo-immuno-electron microscopy. Int Immunol 2:113-125

Thams S, Brodin P, Plantman S, Saxelin R, Karre K, Cullheim S (2009) Classical major histocompatibility complex class I molecules in motoneurons: new actors at the neuromuscular junction. J Neurosci 29:13503-13515 